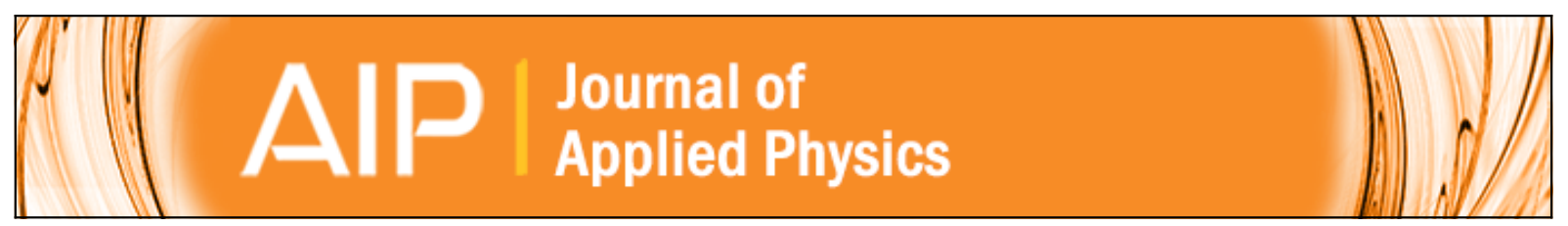

\title{
Magnetic and electronic properties of Fe304/graphene heterostructures: First principles perspective
}

Wenbo Mi, Hua Yang, Yingchun Cheng, Guifeng Chen, and Haili Bai

Citation: Journal of Applied Physics 113, 083711 (2013); doi: 10.1063/1.4793590

View online: http://dx.doi.org/10.1063/1.4793590

View Table of Contents: http://scitation.aip.org/content/aip/journal/jap/113/8?ver=pdfcov

Published by the AIP Publishing

\section{Articles you may be interested in}

Magnetic property and possible half-metal behavior in Co-doped graphene

J. Appl. Phys. 117, 084311 (2015); 10.1063/1.4913387

Systematic study of electronic and magnetic properties for Cu12- x TM x Sb4S13 (TM=Mn, Fe, Co, Ni, and Zn) tetrahedrite

J. Appl. Phys. 115, 143702 (2014); 10.1063/1.4871265

Magnetization of bilayer graphene with interplay between monovacancy in each layer

J. Appl. Phys. 114, 084313 (2013); 10.1063/1.4819913

First-principles study of the structural and magnetic properties of iron indium nitride

J. Appl. Phys. 97, 10D309 (2005); 10.1063/1.1847849

Electronic structure of Li 3 FeN 2 , a nearly half-ferromagnetic metal?

J. Appl. Phys. 93, 6885 (2003); 10.1063/1.1541636

MIT LINCOLN

LABORATORY CAREERS

Discover the satisfaction of innovation and service

to the nation
- Space Control

- Air \& Missile Defense

- Communications Systems \& Cyber Security

- Intelligence, Surveillance and

Reconnaissance Systems

- Advanced
Electronics
- Tactical Systems
- Homeland
Protection
- Air Traffic Control

LINCOLN LABORATORY

MassachusetTs Institute of TeChNOLOgY

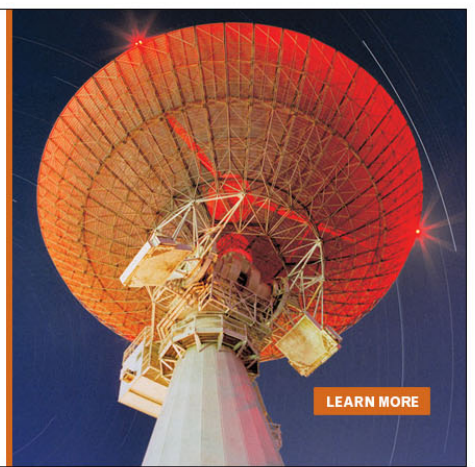




\title{
Magnetic and electronic properties of $\mathrm{Fe}_{3} \mathrm{O}_{4} /$ graphene heterostructures: First principles perspective
}

\author{
Wenbo Mi, ${ }^{1}$ a) Hua Yang, ${ }^{1}$ Yingchun Cheng, ${ }^{2}$ Guifeng Chen, ${ }^{3}$ and Haili Bai ${ }^{1}$ \\ ${ }^{1}$ Tianjin Key Laboratory of Low Dimensional Materials Physics and Preparation Technology, \\ Institute of Advanced Materials Physics, Faculty of Science, Tianjin University, Tianjin 300072, China \\ ${ }^{2}$ PSE Division, KAUST, Thuwal 23955-6900, Kingdom of Saudi Arabia \\ ${ }^{3}$ School of Material Science and Engineering, Hebei University of Technology, Tianjin 300130, \\ People's Republic of China
}

(Received 29 January 2013; accepted 12 February 2013; published online 27 February 2013)

\begin{abstract}
Magnetic and electronic properties of $\mathrm{Fe}_{3} \mathrm{O}_{4}(111)$ /graphene heterostructures are investigated by first principles calculations. Different structural models have been considered, which differ in the interface termination of $\mathrm{Fe}_{3} \mathrm{O}_{4}(111)$ surface with respect to the same monolayer graphene. In three models, the magnetic moment of $\mathrm{Fe}(\mathrm{A})$ has a major change due to less $\mathrm{O}$ atoms surrounding $\mathrm{Fe}(\mathrm{A})$ atoms than $\mathrm{Fe}(\mathrm{B})$. Magnetic moment is enhanced by $8.5 \%, 18.5 \%$, and $8.7 \%$ for models (a), (b), and (c), respectively. Furthermore, the spin polarization of models (a) and (c) is lowered due to the simultaneous occurrence of density of states of spin-up $\mathrm{Fe}(\mathrm{A})$ and spin-down $\mathrm{Fe}(\mathrm{B})$ at Fermi lever. The spin polarization of model (b) remains the same as that of bulk $\mathrm{Fe}_{3} \mathrm{O} 4$. Our results suggest that different interface terminations and $\mathrm{Fe}(\mathrm{A})$ play an important role in determining the magnetism strength and spin polarization. (C) 2013 American Institute of Physics.
\end{abstract}

[http://dx.doi.org/10.1063/1.4793590]

\section{INTRODUCTION}

Graphene, a two-dimensional (2D) single atomic layer of graphite, has attracted a great deal of interest due to its novel electronic properties. ${ }^{1-6}$ The band structure of graphene possesses conical electron and hole pockets which meet only at $\mathrm{K}$ points of Brillouin zone in momentum space. ${ }^{7,8}$ Due to the linear dependence of energy on momentum, carriers behave as effectively massless and have an effective speed of light of $10^{6} \mathrm{~m} / \mathrm{s}$, together with a large spin-relaxation length, ${ }^{1}$ which makes it a promising candidate for spintronics devices. Recently, many experiments focused on graphene spin-valve devices by utilizing ferromagnetic metal as electrodes. ${ }^{9,10}$ As alternative ferromagnetic materials, ferromagnetic halfmetallic oxides are potential to be the spin injection sources because they have high spin polarization, environmental stability, and efficient spin injection. ${ }^{11} \mathrm{Fe}_{3} \mathrm{O}_{4}$ was predicted to be half-metallic with a high Curie temperature of $858 \mathrm{~K}^{12-15}$ If $\mathrm{Fe}_{3} \mathrm{O}_{4}$ was chosen as a spin injector to perform spin injection into graphene, new spintronics devices will be set up. However, the results on $\mathrm{Fe}_{3} \mathrm{O}_{4}$ /graphene heterostructures have not been widely reported so far. Experimentally, (100), (110), and (111) oriented epitaxial $\mathrm{Fe}_{3} \mathrm{O}_{4}$ films have been fabricated, in which $\mathrm{Fe}_{3} \mathrm{O}_{4}(111)$ plane is composed of atoms with hexagon shape that corresponds to the hexagon of $\mathrm{C}$ atoms in grapheme. Hence, we choose $\mathrm{Fe}_{3} \mathrm{O}_{4}(111)$ /graphene interface to investigate the magnetic and electronic properties of half-metallic oxide/graphene interfaces. In this paper, magnetic and electronic properties of $\mathrm{Fe}_{3} \mathrm{O}_{4}(111)$ /graphene heterostructures have been investigated by first principles

\footnotetext{
a) Author to whom correspondence should be addressed. Electronic mail: miwenbo@tju.edu.cn.
}

calculations. Spin polarization of models (a) and (c) is lowered, but spin polarization of model (b) remains the same as that of bulk $\mathrm{Fe}_{3} \mathrm{O} 4$. Different interfacial terminations and $\mathrm{Fe}(\mathrm{A})$ play an important role in determining the magnetism and spin polarization.

\section{CALCULATION DETAILS AND MODEL}

All the spin-polarized calculations were performed within projector augmented wave (PAW) method $^{16,17}$ as implemented in the computational code of Vienna ab initio simulation package, ${ }^{18}$ based on the density-functional theory (DFT). Exchange-correlation potential was treated by generalized gradient approximation, according to Perdew-Burke-Ernzerhof. ${ }^{19}$ In order to find the theoretical equilibrium static geometries a standard plane-wave basis set with a kinetic-energy cutoff of $520 \mathrm{eV}$ was used in the geometry optimization process and static calculations. A $\Gamma$-centered $5 \times 5 \times 5 k$-point mesh was performed for the bulk calculations of $\mathrm{Fe}_{3} \mathrm{O}_{4}$, while we adopted a $\Gamma$-centered $5 \times 5 \times 1$ and $10 \times 10 \times 1$ for the static and density of states (DOS) calculations of monolayer graphene, respectively. Calculations were converged to $10^{-5} \mathrm{eV}$ and the structures were relaxed until the largest force became less than $0.03 \mathrm{eV} / \AA$.

Bulk $\mathrm{Fe}_{3} \mathrm{O}_{4}$ crystallizing in the inverted spinel structure (Space group: $F d 3 m$ ) has chemical formula $\left[\mathrm{Fe}^{\downarrow}\right]_{\mathrm{A}}\left[\mathrm{Fe}_{2}{ }^{\uparrow}\right]_{\mathrm{B}} \mathrm{O}_{4}$ with a experimental lattice constant of $8.39 \AA$. In inverse spinel structure, the tetrahedron $\mathrm{A}$ sites are occupied by $\mathrm{Fe}^{3+}$ ions, while the octahedron $\mathrm{B}$ sites are occupied by an equal number of randomly distributed $\mathrm{Fe}^{2+}$ and $\mathrm{Fe}^{3+}$ ions. Magnetic moments of $\mathrm{Fe}$ ions in the two sites oppositely oriented, so it can be said that $\mathrm{Fe}_{3} \mathrm{O}_{4}$ is a ferrimagnet with a 
total magnetic moment of $4 \mu_{\mathrm{B}} / \mathrm{Fe}_{3} \mathrm{O}_{4}$, as indicated by the arrows in the chemical formula given above. ${ }^{20,21}$ Graphene is a monolayer of carbon atoms packed into a dense honeycomb crystal structure, which can be obtained by mechanical exfoliation from graphite. Its honeycomb structure contains a bipartite lattice, formed by two interpenetrating triangular sublattices. There are strong covalent bonds between carbon atoms arranged in a honeycomb lattice. The nearest neighbor distance in graphene is $1.42 \AA{ }^{22}$

$\mathrm{Fe}_{3} \mathrm{O}_{4}$ /graphene interfaces was simulated by building up the bilayers structure consisting of $\mathrm{Fe}_{3} \mathrm{O}_{4}(111)$ and monolayer graphene because $\mathrm{Fe}_{3} \mathrm{O}_{4}(111)$ plane was composed of atoms with hexagon shape that corresponds to the hexagon of $\mathrm{C}$ atoms in grapheme sheet. The supercell was modeled by containing monolayer graphene attached to one unit cell of $\mathrm{Fe}_{3} \mathrm{O}_{4}(111)$ with three different terminations plus a vacuum layer of $10 \AA$. The supercell contains three models because $\mathrm{Fe}_{3} \mathrm{O}_{4}(111)$ surface has three different terminations, as shown in Fig. 1. $\mathrm{Fe}_{3} \mathrm{O}_{4}$ (111) is composed of alternate $\mathrm{Fe}(\mathrm{A}), \mathrm{Fe}(\mathrm{B})$, and $\mathrm{O}$ layers, while graphene has only one layer. By employing the periodic boundary conditions, each model contains an interface: model (a) contains the $\mathrm{O}-\mathrm{C}$ interface; model (b) contains the $\mathrm{Fe}(\mathrm{B})-\mathrm{C}$ interface; model (c) contains the $\mathrm{Fe}(\mathrm{A})-\mathrm{C}$ interface. In order to make the surface unit cell of $\mathrm{Fe}_{3} \mathrm{O}_{4}(111)$ and monolayer graphene lattice matched, the surface unit cell of $\mathrm{Fe}_{3} \mathrm{O}_{4}(111)$ has $p(2 \times 2)$ periodicity with a lattice constant of $11.86 \AA$, while monolayer graphene has $5 \times 5$ periodicity with a lattice constant of $12.3 \AA$. There is a minor mismatch in lattice constant between graphene and $\mathrm{Fe}_{3} \mathrm{O}_{4}(111)$ surface. Thus, for the present supercells, to compensate lattice mismatch an average lattice constant of $12.08 \AA$ is adopted for both the $\mathrm{Fe}_{3} \mathrm{O}_{4}$ and graphene regions. Density-functional calculations on electronic and atomic structures for $\mathrm{Fe}_{3} \mathrm{O}_{4}(111)$ /graphene heterostructures were performed using $5 \times 5 \times 1$ Monkhorst-Pack mesh of $k$ points in Brillouin zone.

\section{RESULTS AND DISCUSSIONS}

For monolayer graphene, the calculated band structure shows a zero bandgap semiconductor. The valence band maximum (VBM) and conduction band minimum (CBM) meet at $\mathrm{K}$ point called Dirac point, where the effective mass of the hole and electron is nearly zero, leading to the excellent electrical properties. For bulk $\mathrm{Fe}_{3} \mathrm{O}_{4}$, the calculated lattice constant is $8.40 \AA$, which is consistent with experimental value mentioned above. The calculated magnetic moment for $\mathrm{Fe}(\mathrm{A}), \mathrm{Fe}(\mathrm{B})$, and $\mathrm{O}$ ions are approximately
-3.486, 3.569, and $0.077 \mu_{\mathrm{B}} /$ atom, as listed in Table I, respectively, leading a net moment of $\sim 4 \mu_{\mathrm{B}} / \mathrm{Fe}_{3} \mathrm{O}_{4}$. The results are consistent with the previous theoretical and experimental results. ${ }^{23-25}$ The partial DOS of Fe(A) has a band gap in both the spin-up and spin-down channels, which indicates that $\mathrm{Fe}(\mathrm{A})$ ions are insulating. However, DOS of $\mathrm{Fe}(\mathrm{B})$ has only finite values at Fermi energy in spin-down channel, and shows a half-metallic feature, as shown in Fig. 2(a). As a result, bulk $\mathrm{Fe}_{3} \mathrm{O}_{4}$ is half-metallic. ${ }^{26,27}$ In Fig. 2, the symbol "IF-Fe-A-4" is the atomic number, where IF is the "interface", Fe-A is the Fe ions at A sites, 4 is the atomic number of Fe ions at $\mathrm{A}$ sites. The same definition was presented in other figures.

Figure 2 shows the calculated partial DOS of O-C interface contained in model (a), which is obtained by projecting on $\mathrm{Fe}(\mathrm{A}), \mathrm{Fe}(\mathrm{B})$, and $\mathrm{O}$ layers from the $\mathrm{Fe}_{3} \mathrm{O}_{4}$ component in the supercell. When $\mathrm{Fe}_{3} \mathrm{O}_{4}$ and graphene are contacted to form the interface, the most surprising feature is that the half-metallic behavior of $\mathrm{Fe}_{3} \mathrm{O}_{4}$ caused by $\mathrm{Fe}(\mathrm{B})$ ions on the fifth layer is nearly disappeared, while the partial DOS of $\mathrm{Fe}(\mathrm{B})$ ions on the second layer near the interface remains the half-metallic feature, as shown in Fig. 2(a). Meanwhile, it is observed that only the spin-up conduction band (CB) of $\mathrm{Fe}(\mathrm{A})$ ions on the forth layer shifts considerably to lower energy and pass through Fermi level, leading to $100 \%$ spin polarization, which makes the corresponding magnetic moment of $\mathrm{Fe}(\mathrm{A})$ ions decreases as compared to bulk $\mathrm{Fe}_{3} \mathrm{O}_{4}$. In addition, the spin-down valence band (VB) of $\mathrm{Fe}(\mathrm{A})$ ions on the sixth layer passes through the Fermi level, resulting in $100 \%$ spin polarization. Meanwhile, the magnetic moment of $\mathrm{Fe}(\mathrm{A})$ ions on the sixth layer decreases as compared to bulk $\mathrm{Fe}_{3} \mathrm{O}_{4}$, as shown in Table I. The simultaneous occurrence of pin-up $\mathrm{Fe}(\mathrm{A})$ and spin-down $\mathrm{Fe}(\mathrm{B})$ leads to low spin polarization as compared to bulk $\mathrm{Fe}_{3} \mathrm{O}_{4}$. Figure 2(b) shows the partial DOS of $\mathrm{O}$ atoms. The $\mathrm{O}-2 p$ states on the first layer obviously shift to higher energy by $0.5 \mathrm{eV}$, and the strong spin splitting DOSs in both the channels indicate that the magnetic moment of $\mathrm{O}$ increases as compared to bulk $\mathrm{Fe}_{3} \mathrm{O}_{4}$. However, the $\mathrm{O}-2 p$ states on the seventh layer obviously shift $1.3 \mathrm{eV}$ to higher energy and the VB in spin-down channel comes across Fermi level, and it is relatively symmetrical, which results in the reducing magnetic moment as compared to bulk $\mathrm{Fe}_{3} \mathrm{O}_{4}$ (seen in Table I). Furthermore, there are two kinds of $\mathrm{O}$ atoms on the third layer with different magnetic moment, which is possibly due to the fact that $\mathrm{O}$ $2 p$ states with large magnetic moment have a stronger hybridization with both $\mathrm{Fe}(\mathrm{A})$ and $\mathrm{Fe}(\mathrm{B})$ ions $3 d$ states than $\mathrm{O}$ atoms with small magnetic moment. Figure 2(c) shows the partial DOS of $\mathrm{C}$ atoms. It can be clearly seen from the

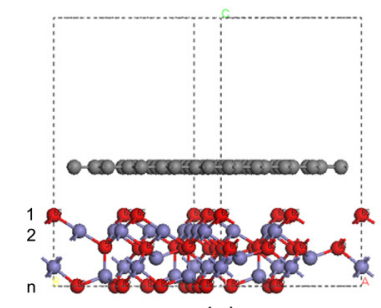

(a)

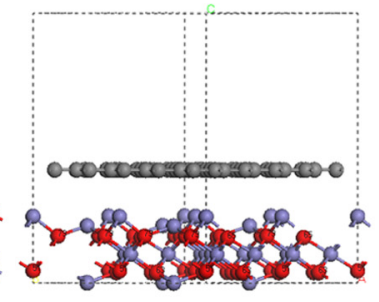

(b)

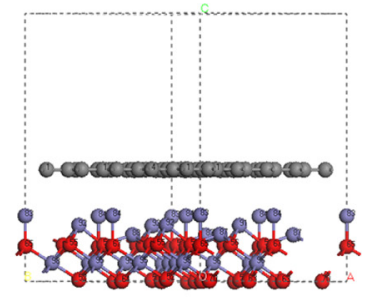

(c)
FIG. 1. The supercell structure of $\mathrm{Fe}_{3} \mathrm{O}_{4}$ /graphene: model (a) contains the interface of $\mathrm{O}-\mathrm{C}$; model (b) contains the interface of $\mathrm{Fe}(\mathrm{B})-\mathrm{C}$; model (c) contains the interface of $\mathrm{Fe}(\mathrm{A})-\mathrm{C}$. The left/right side is the $\mathrm{Fe}_{3} \mathrm{O}_{4} /$ graphene, respectively. The red spheres stand for oxygen atoms, the blue spheres stand for $\mathrm{Fe}$ atoms of $\mathrm{Fe}_{3} \mathrm{O}_{4}$, and the dark gray spheres stand for $\mathrm{C}$ atoms. 
TABLE I. The calculated magnetic moment $m\left(\mu_{\mathrm{B}}\right)$ of per atom including $\mathrm{Fe}$ and $\mathrm{O}$ in the supercell $\mathrm{Fe}_{3} \mathrm{O}_{4}(111) /$ graphene model (a), as compared to that of the bulk $\mathrm{Fe}_{3} \mathrm{O}_{4}$.

\begin{tabular}{lccc}
\hline \hline Layer & $\mathrm{FO}-\mathrm{Fe}(\mathrm{A})$ & $\mathrm{FO}-\mathrm{Fe}(\mathrm{B})$ & $\mathrm{FO}-\mathrm{O}$ \\
\hline 1 & $\ldots$ & $\ldots$ & 0.381 \\
2 & $\ldots$ & 3.632 & $\ldots$ \\
3 & $\ldots$ & $\ldots$ & $\mathrm{O}(51) 0.249$ \\
& & & $\mathrm{O}(63) 0.113$ \\
4 & -3.234 & $\ldots$ & $\ldots$ \\
5 & - & 3.423 & $\ldots$ \\
6 & -3.3285 & $\ldots$ & $\ldots$ \\
7 & $\ldots$ & $\ldots$ & -0.0143 \\
Bulk & -3.486 & 3.569 & 0.077 \\
\hline \hline
\end{tabular}

figure that the graphene is a zero bandgap semiconductor. Although the C DOS from the interface still remain symmetrical, the $\mathrm{VB}$ in both the spin-up and spin-down channels pass through the Fermi level, destroying the particular electronic structure.

Figure 3 shows the calculated partial DOS of the $\mathrm{Fe}(\mathrm{B})-\mathrm{C}$ interface contained in model (b). The half-metallic behavior of $\mathrm{Fe}_{3} \mathrm{O}_{4}$ caused by $\mathrm{Fe}(\mathrm{B})$ ions on the first layer is nearly vanished, while the partial DOS of $\mathrm{Fe}(\mathrm{B})$ ions on the forth layer far away the interface remains the half-metallic feature, as shown in Fig. 3(a). This is different from the O-C interface. The DOS of $\mathrm{Fe}(\mathrm{A})$ ion on the interface has only small change as compared to bulk $\mathrm{Fe}_{3} \mathrm{O}_{4}$. All the DOSs of $\mathrm{Fe}(\mathrm{A})$ ions remain an insulating behavior. But the magnetic moment of $\mathrm{Fe}(\mathrm{A})$ ions on both the second and sixth layer decreases as compared to bulk $\mathrm{Fe}_{3} \mathrm{O}_{4}$, as seen in Table II. The above results suggest that the interfacial influence on electronic structure becomes less as the distance between the atoms and interface increases. Figure 3(b) shows the partial DOS of $\mathrm{O}$ atoms. All the $\mathrm{O}-2 p$ states obviously shift to higher energy by $0.5 \mathrm{eV}$, and DOSs in both the channels remain insulating. The $\mathrm{O}(65)-2 p$ states on the third layer have a strong spin splitting, resulting in the corresponding magnetic moment increasing as compared to bulk $\mathrm{Fe}_{3} \mathrm{O}_{4}$, while $\mathrm{O}(79)-2 p$ states on the third layer are relatively symmetrical and have the same magnetic moment as compared to bulk $\mathrm{Fe}_{3} \mathrm{O}_{4}$. The $\mathrm{O}$ atoms on the fifth layer have the similar behavior as that on the third layer. There are two kinds of $\mathrm{O}$ atoms with different magnetic moment on both the third layer and fifth layer, which may be due to the fact that $\mathrm{O}$
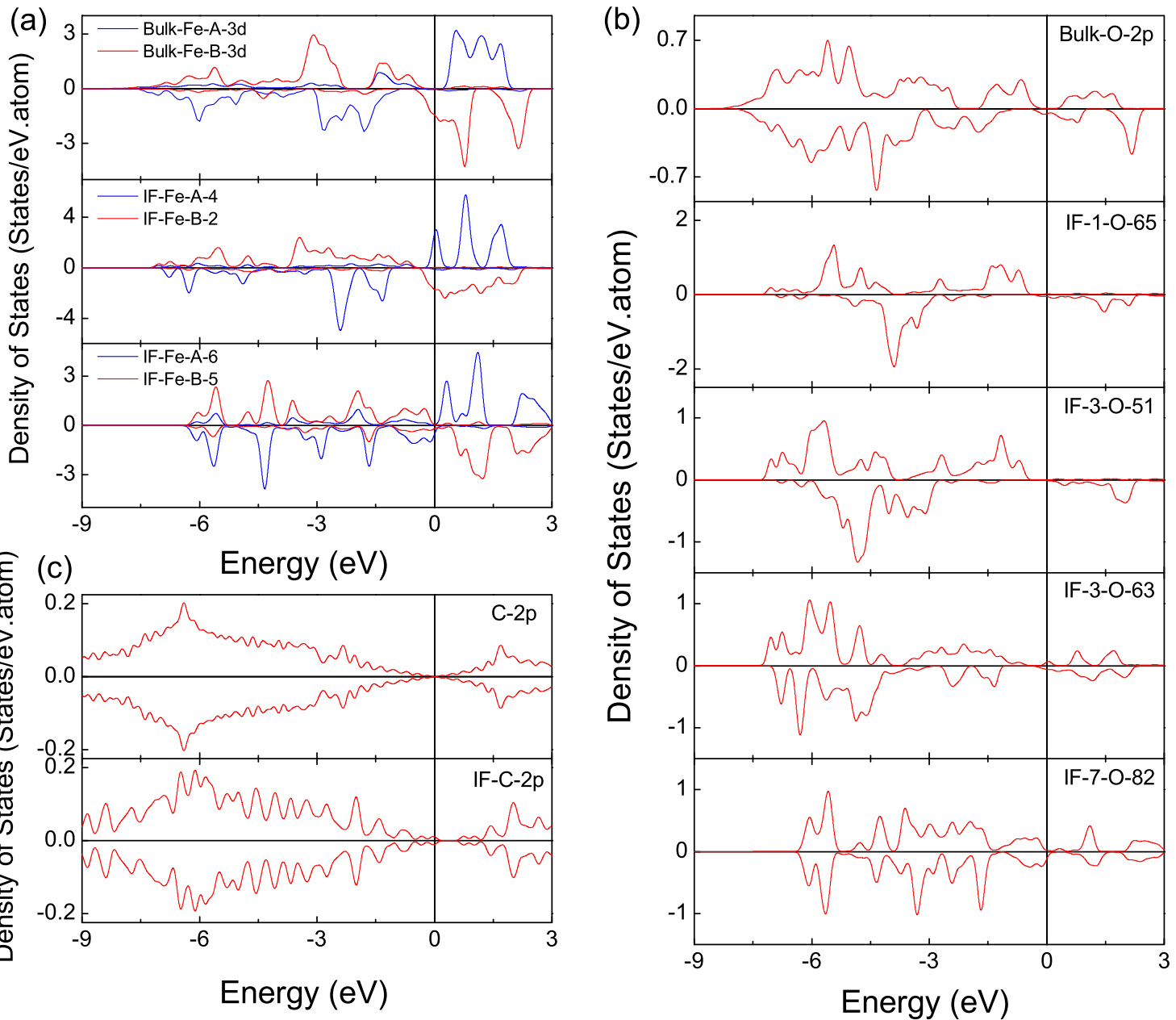

FIG. 2. (a) The partial DOS obtained for the fully relaxed $\mathrm{Fe}_{3} \mathrm{O}_{4} /$ graphene model (a), as compared to the bulk Fe $\mathrm{O}_{4}$ compounds. The blue/red line stands for $\mathrm{Fe}(\mathrm{A}) / \mathrm{Fe}(\mathrm{B})$ atoms. (b) The contrast between the bulk $\mathrm{O}$ atoms and $\mathrm{O}$ atoms at the different sites of the interface in the model (a). (c) The contrast between the bulk $\mathrm{C}$ atoms and $\mathrm{C}$ atoms of the interface in the model (a). The Fermi energy is indicated by the vertical dashed line and the Fermi level is set to 0 eV. 

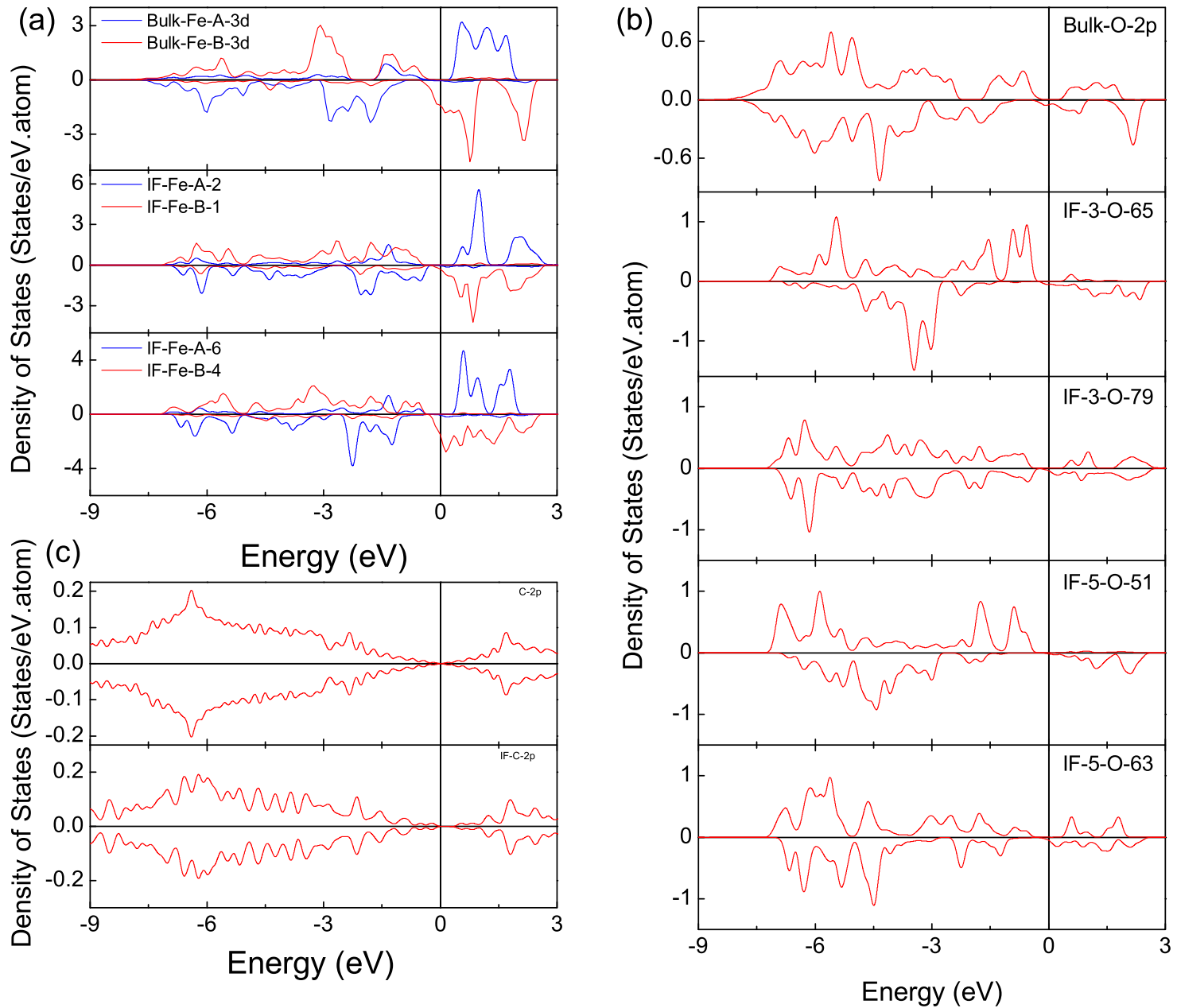

FIG. 3. (a) The partial DOS obtained for the fully relaxed $\mathrm{Fe}_{3} \mathrm{O}_{4} /$ graphene model (b), as compared to the bulk $\mathrm{Fe}_{3} \mathrm{O}_{4}$ compounds. The blue/red line stands for $\mathrm{Fe}(\mathrm{A}) / \mathrm{Fe}(\mathrm{B})$ atoms. (b) The contrast between the bulk $\mathrm{O}$ atoms and $\mathrm{O}$ atoms at the different sites of the interface in the model (b). (c) The contrast between the bulk $\mathrm{C}$ atoms and $\mathrm{C}$ atoms of the interface in the model (b).The Fermi energy is indicated by the vertical dashed line and the Fermi level is set to $0 \mathrm{eV}$.

atoms with small magnetic moment connect with both $\mathrm{Fe}(\mathrm{A})$ and $\mathrm{Fe}(\mathrm{B})$ ions, while $\mathrm{O}$ atoms with large magnetic moment only connect with $\mathrm{Fe}(\mathrm{B})$ ions. The increasing magnetic moment is due to the strong hybridization between $\mathrm{O}$ and $\mathrm{Fe}(\mathrm{B})$ atoms. Figure 3(c) shows the partial DOS of $\mathrm{C}$ atoms. It can be clearly seen that DOS of $\mathrm{C}$ at the interface still remains symmetrical, but DOSs in both the spin-up and spin-

TABLE II. The calculated magnetic moment $m\left(\mu_{\mathrm{B}}\right)$ of per atom including $\mathrm{Fe}$ and $\mathrm{O}$ in the supercell $\mathrm{Fe}_{3} \mathrm{O}_{4}(111)$ /graphene model (b), as compared to that of the bulk $\mathrm{Fe}_{3} \mathrm{O}_{4}$.

\begin{tabular}{lccc}
\hline \hline & $\mathrm{FO}-\mathrm{Fe}(\mathrm{A})$ & $\mathrm{FO}-\mathrm{Fe}(\mathrm{B})$ & $\mathrm{FO}-\mathrm{O}$ \\
\hline 1 & $\ldots$ & 3.456 & $\ldots$ \\
2 & -3.154 & $\ldots$ & $\ldots$ \\
3 & $\ldots$ & $\ldots$ & $\mathrm{O}(65) 0.398$ \\
& $\ldots$ & 3.688 & $\ldots$ \\
4 & $\ldots$ & $\ldots$ & $\mathrm{O}(51) 0.325$ \\
5 & $\ldots$ & $\ldots$ & $\mathrm{O}(63) 0.091$ \\
& & 3.569 & $\ldots$ \\
6 & -3.099 & & 0.077 \\
Bulk & -3.486 & & \\
\hline \hline
\end{tabular}

down channels have a bandgap of $0.36 \mathrm{eV}$, destroying the particular electronic structure.

Figure 4 shows the calculated partial DOS of $\mathrm{Fe}(\mathrm{A})-\mathrm{C}$ interface contained in model (c). We observed the similar behavior as $\mathrm{Fe}(\mathrm{B})-\mathrm{C}$ interface that the half-metallic behavior caused by $\mathrm{Fe}(\mathrm{B})$ ions on the second layer nearly disappears, while the partial DOS of $\mathrm{Fe}(\mathrm{B})$ ions on the fifth layer far away the interface remains the half-metallic feature, as shown in Fig. 4. However, the spin-up CB of Fe(A)-83 ions on the first layer shifts considerably to lower energy and pass through the Fermi level, leading to $100 \%$ spin polarization, which makes the corresponding magnetic moment of $\mathrm{Fe}(\mathrm{A})$ 83 ions decreases as compared to bulk $\mathrm{Fe}_{3} \mathrm{O}_{4}$, as shown in Table III. Meanwhile, the spin-down DOS of Fe(A)-84 ion on the first layer pass through the Fermi level, resulting in the $100 \%$ spin polarization. The phenomenon is related with the fact that both the edges of monolayer graphene bend toward $\mathrm{Fe}_{3} \mathrm{O}_{4}(111)$ surface. The occurrence of spin-up $\mathrm{Fe}(\mathrm{A})$ would lower the spin polarization at Fermi level as compared to bulk $\mathrm{Fe}_{3} \mathrm{O}_{4}$. DOSs of $\mathrm{Fe}(\mathrm{A})$ ions on the third layer display an insulating character, which is consistent with the bulk $\mathrm{Fe}_{3} \mathrm{O}_{4}$ properties. Figure 5 shows the partial DOS of $\mathrm{O}$ atoms. The O-2p states shift to higher energy and the DOSs 

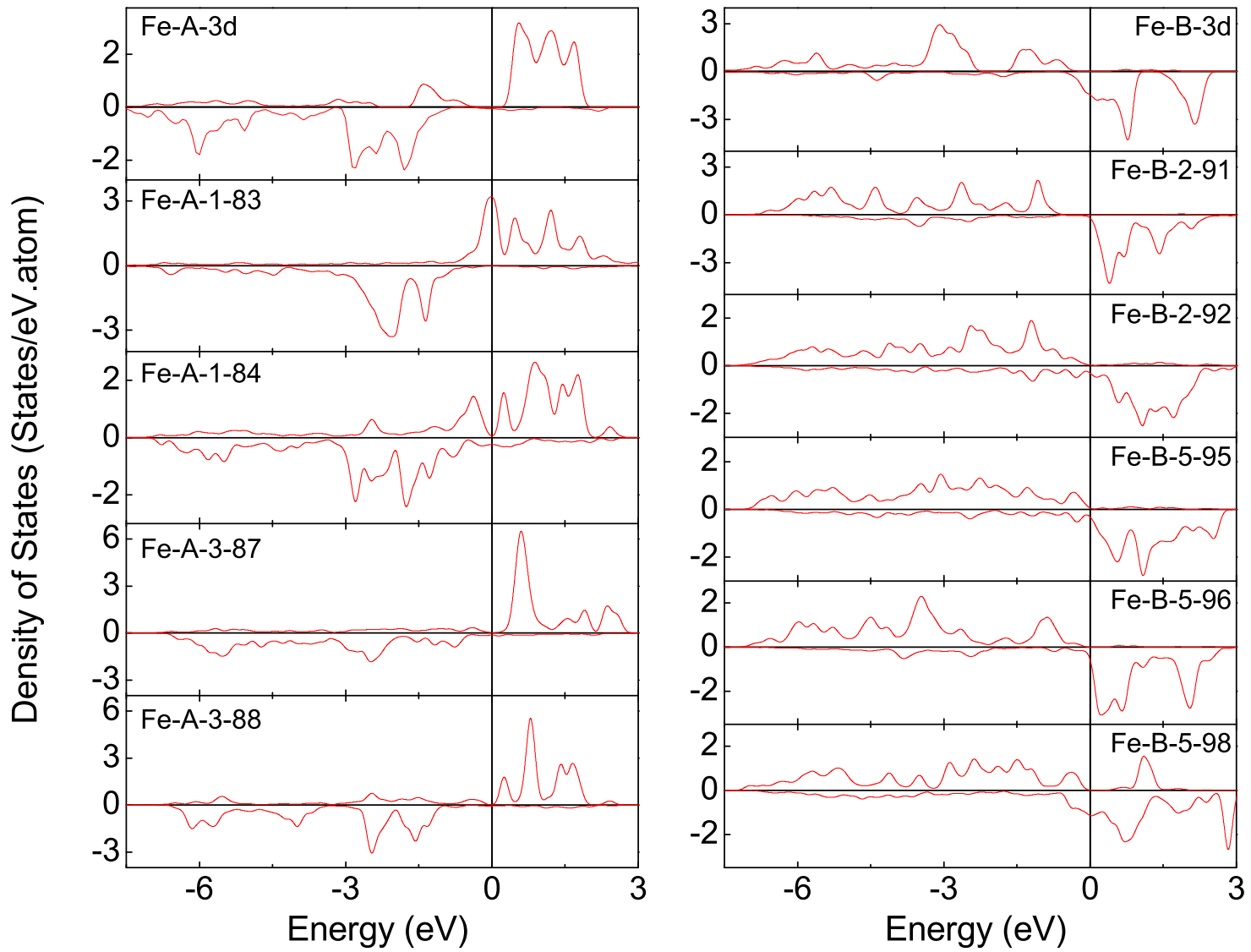

FIG. 4. The partial DOS obtained for the fully relaxed $\mathrm{Fe}_{3} \mathrm{O}_{4} /$ graphene model (c), as compared to the bulk $\mathrm{Fe}_{3} \mathrm{O}_{4}$ compounds. The blue/red line stands for $\mathrm{Fe}(\mathrm{A}) / \mathrm{Fe}(\mathrm{B})$ atoms. The Fermi energy is indicated by the vertical dashed line and the Fermi level is set to $0 \mathrm{eV}$.

TABLE III. The calculated magnetic moment $m\left(\mu_{\mathrm{B}}\right)$ of per atom including $\mathrm{Fe}$ and $\mathrm{O}$ in the supercell $\mathrm{Fe}_{3} \mathrm{O}_{4}(111) /$ graphene model (c), as compared to that of the bulk $\mathrm{Fe}_{3} \mathrm{O}_{4}$.

\begin{tabular}{|c|c|c|c|}
\hline & $\mathrm{FO}-\mathrm{Fe}(\mathrm{A})$ & $\mathrm{FO}-\mathrm{Fe}(\mathrm{B})$ & FO-O \\
\hline 1 & $\begin{array}{l}\mathrm{Fe}(83)-2.894 \\
\mathrm{Fe}(84)-2.697\end{array}$ & $\ldots$ & $\ldots$ \\
\hline 2 & $\ldots$ & $\begin{array}{l}\mathrm{Fe}(91) 3.650 \\
\mathrm{Fe}(92) 3.305\end{array}$ & $\ldots$ \\
\hline 3 & $\begin{array}{l}\mathrm{Fe}(87)-3.479 \\
\mathrm{Fe}(88)-3.223\end{array}$ & $\ldots$ & $\ldots$ \\
\hline 4 & $\ldots$ & $\cdots$ & $\begin{array}{l}\mathrm{O}(55) 0.154 \\
\mathrm{O}(56) 0.392 \\
\mathrm{O}(57)-0.06 \\
\mathrm{O}(65) 0.074 \\
\mathrm{O}(67) 0.122\end{array}$ \\
\hline 5 & $\ldots$ & $\begin{array}{l}\mathrm{Fe}(95) 3.519 \\
\mathrm{Fe}(96) 3.846 \\
\mathrm{Fe}(98) 2.704\end{array}$ & $\ldots$ \\
\hline 6 & $\ldots$ & $\ldots$ & $\begin{array}{c}\mathrm{O}(51) 0.488 \\
\mathrm{O}(52) 0.366 \\
\mathrm{O}(63) 0.173 \\
\mathrm{O}(64) 0.060 \\
\mathrm{O}(70)-0.015\end{array}$ \\
\hline Bulk & -3.486 & 3.569 & 0.077 \\
\hline
\end{tabular}

in both the channel remain insulating. Interestingly, $\mathrm{O}$ atoms in the same layer have different magnetic moments, which may be due to the difference of $\mathrm{Fe}$ ions surrounding $\mathrm{O}$ atoms. Figure 6 shows the partial DOS of C atoms. It can be clearly seen that DOSs of $\mathrm{C}$ atoms at the interface changed significantly, and DOSs of C-1 atom have finite DOS and pass through Fermi level only in the spin-up channel. While DOSs of C-4 atom have the similar shape as that of monolayer graphene.

In order to clearly show the magnetic properties, the calculated $m$ for $\mathrm{Fe}$ and $\mathrm{O}$ ions in the models (a), (b), and (c) are presented in Tables I-III, respectively. The numbers in the parentheses behind the atoms in these tables are presented in Fig. 1. For models (a) and (b), the magnetic moment of the whole supercell is enhanced by $8.5 \%$ and $18.5 \%$, respectively, which is attributed to the increased magnetic moment from $\mathrm{O}$ and the reduced magnetic moment from $\mathrm{Fe}(\mathrm{A})$ atoms in $\mathrm{Fe}_{3} \mathrm{O}_{4}$. Furthermore, the corresponding magnetic moment of $\mathrm{Fe}_{3} \mathrm{O}_{4}$ formula unit increases to 4.3413 and $4.7395 \mu_{\mathrm{B}}$, respectively. Yet, for the model (c), the magnetic moment of the system is also enhanced by $8.7 \%$, which results from the combined action of the increasing magnetic moment of $\mathrm{Fe}(\mathrm{A})$ and $\mathrm{O}$ atoms as well as the reduced magnetic moment of $\mathrm{Fe}(\mathrm{B})$ atoms. Also, we find that the magnetic moment of $\mathrm{Fe}(\mathrm{A})$ atoms has a major change in all of the three model because the less $\mathrm{O}$ atoms surrounding $\mathrm{Fe}(\mathrm{A})$ atoms than $\mathrm{Fe}(\mathrm{B})$ atoms. 

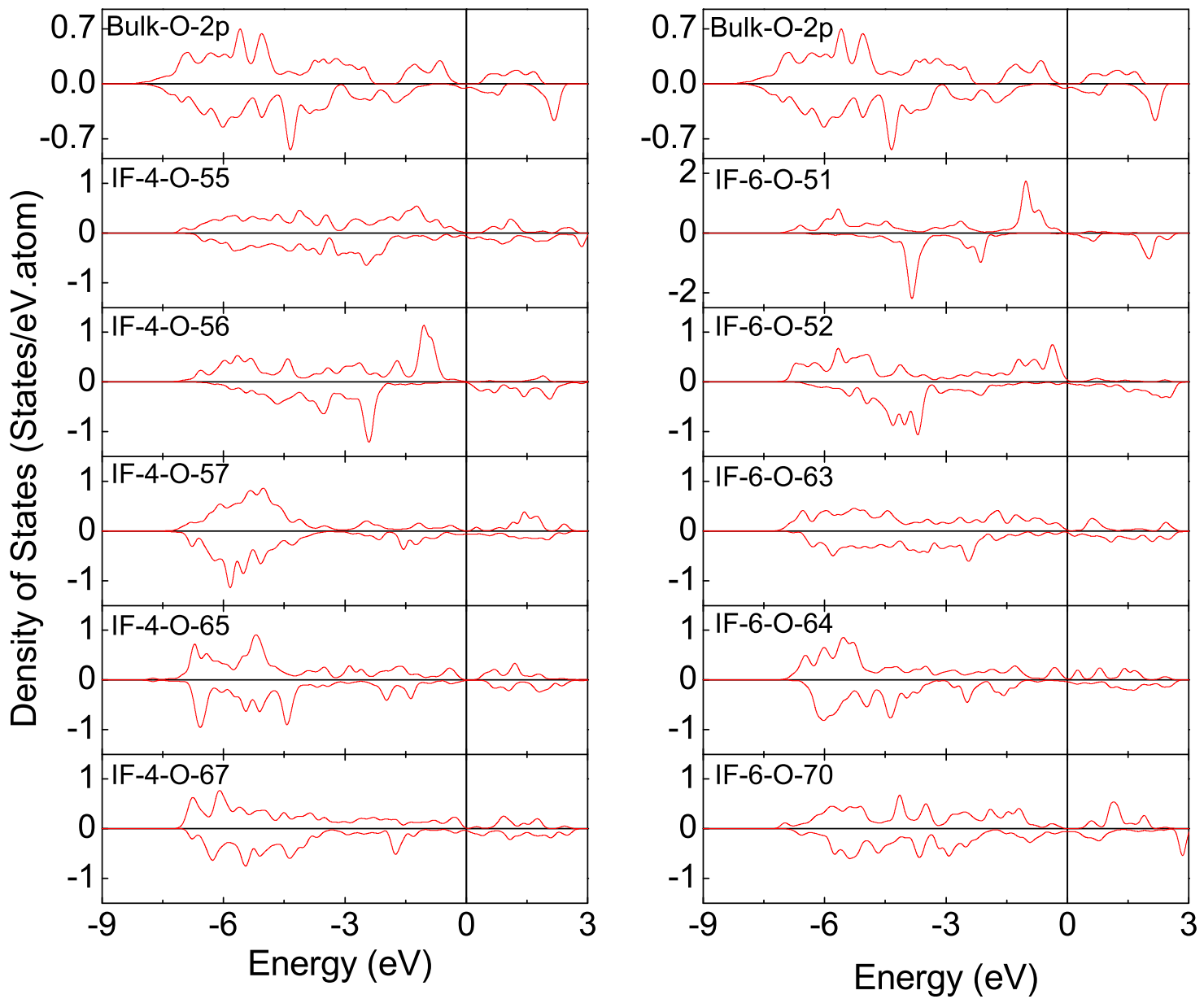

FIG. 5. The contrast between the bulk $\mathrm{O}$ atoms and $\mathrm{O}$ atoms at the different sites of the interface in the model (c). The Fermi energy is indicated by the vertical dashed line and the Fermi level is set to $0 \mathrm{eV}$.

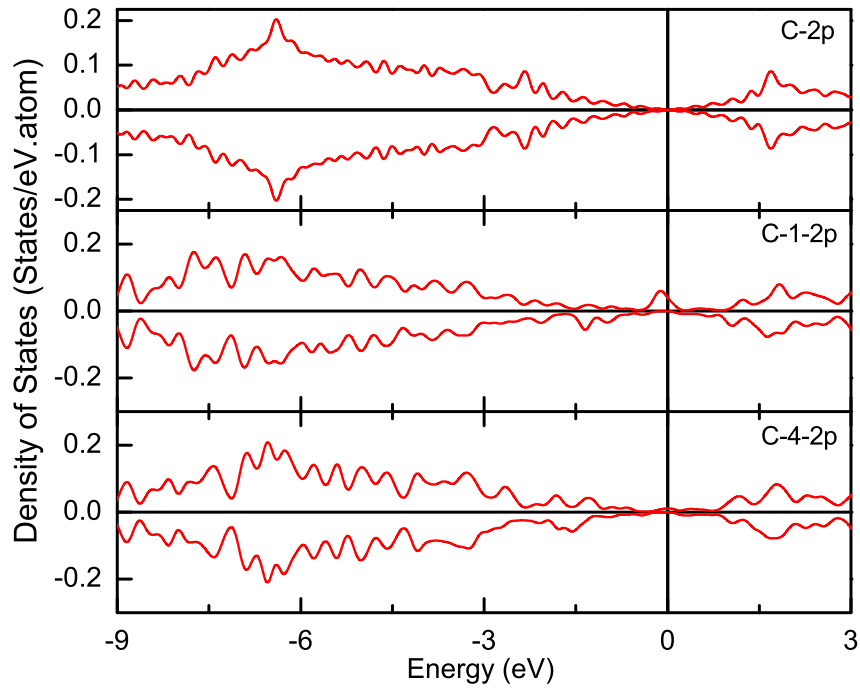

FIG. 6. The contrast between the bulk $\mathrm{C}$ atoms and $\mathrm{C}$ atoms of the interface in the model (c). The Fermi energy is indicated by the vertical dashed line and the Fermi level is set to $0 \mathrm{eV}$.

\section{CONCLUSION}

We have performed first-principles calculations to investigate the electronic and magnetic properties of $\mathrm{Fe}_{3} \mathrm{O}_{4}(111) /$ graphene heterostructure. The magnetic moment enhances
$8.5 \%, 18.5 \%$, and $8.7 \%$ for models (a), (b), and (c), respectively. In three models, the magnetic moment of the $\mathrm{Fe}(\mathrm{A})$ has a major change, which is caused by the less $\mathrm{O}$ atoms surrounding $\mathrm{Fe}(\mathrm{A})$ atoms than $\mathrm{Fe}(\mathrm{B})$ atoms. Furthermore, spin polarization of models (a) and (c) is lowered due to the simultaneous occurrence of DOS of spin-up $\mathrm{Fe}(\mathrm{A})$ and spin-down $\mathrm{Fe}(\mathrm{B})$ at Fermi level, while the spin polarization of model (b) remain the same as that of bulk $\mathrm{Fe}_{3} \mathrm{O} 4$. Therefore, we would possibly tune the interface states by engineering the different interface terminations for optimized performances in spintronics device applications.

\section{ACKNOWLEDGMENTS}

This work was supported by the National Natural Foundation of China (51172126) and the Key Project of Natural Foundation of Tianjin City (12JCZDJC27100).

${ }^{1}$ A. H. Castro Neto, F. Guinea, N. M. R. Peres, K. S. Novoselov, and A. K. Geim, Rev. Mod. Phys. 81, 109 (2009).

${ }^{2}$ Y. B. Zhang, Y. W. Tan, H. L. Stormer, and P. Kim, Nature 438, 201 (2005).

${ }^{3}$ N. Tombros, C. Jozsa, M. Popinciuc, H. T. Jonkman, and B. J. van Wees, Nature 448, 571 (2007).

${ }^{4}$ S. Cho, Y.-F. Chen, and M. S. Fuhrer, Appl. Phys. Lett. 91, 123105 (2007). 
${ }^{5}$ W. Han, W. H. Wang, K. Pi, K. M. McCreary, W. Bao, Y. Li, F. Miao, C. N. Lau, and R. K. Kawakami, Phys. Rev. Lett. 102, 137205 (2009).

${ }^{6}$ K. S. Novoselov, A. K. Geim, S. V. Morozov, D. Jiang, Y. Zhang, S. V. Dubonos, I. V. Grigorieva, and A. A. Firsov, Science 306, 666 (2004).

${ }^{7}$ S. Y. Zhou, G.-H. Gweon, and A. Lanzara, Ann. Phys. 321, 1730 (2006).

${ }^{8}$ K. S. Novoselov, A. K. Geim, S. V. Morozov, D. Jiang, M. I. Katsnelson, I. V. Grigorieva, S. V. Dubonos, and A. A. Firsov, Nature 438, 197 (2005).

${ }^{9}$ E. W. Hill, A. K. Geim, K. Novoselov, F. Schedin, and P. Blake, IEEE Trans. Magn. 42, 2694 (2006).

${ }^{10}$ W. H. Wang, K. Pi, Y. Li, Y. F. Chiang, P. Wei, J. Shi, and R. K. Kawakami, Phys. Rev. B 77, 020402(R) (2008).

${ }^{11}$ L. E. Hueso, J. M. Pruneda, V. Ferrari, G. Burnell, J. P. Valdés-Herrera, B. D. Simons, P. B. Littlewood, E. Artacho, A. Fert, and N. D. Mathur, Nature 445, 410 (2007).

${ }^{12}$ S. Lee, A. Fursina, J. T. Mayo, C. T. Yavuz, V. L. Kolvin, R. G. S. Sofin, I. G. Shvets, and D. Natelson, Nature Mater. 7, 130 (2008).

${ }^{13}$ Z. M. Liao, Y. D. Li, J. Xu, J. M. Zhang, K. Xia, and D. Yu, Nano Lett. 6 , 1087 (2006).

${ }^{14}$ Y. C. Sui, R. Skomski, K. D. Sorge, and D. J. Sellmyer, Appl. Phys. Lett. 84, 1525 (2004).
${ }^{15}$ W. B. Mi, J. J. Shen, E. Y. Jiang, and H. L. Bai, Acta Mater. 55, 1919 (2007).

${ }^{16}$ P. E. Blöchl, Phys. Rev. B 50, 17953 (1994).

${ }^{17}$ G. Kresse and D. Joubert, Phys. Rev. B 59, 1758 (1999).

${ }^{18}$ G. Kresse and J. Furthmuller, Phys. Rev. B 54, 11169 (1996).

${ }^{19}$ J. P. Perdew, K. Burke, and M. Ernzerhof, Phys. Rev. Lett. 77, 3865 (1996).

${ }^{20}$ M. K. Niranjan, J. P. Velev, C. G. Duan, S. S. Jaswal, and E. Y. Tsymbal, Phys. Rev. B 78, 104405 (2008).

${ }^{21}$ T. Kida, S. Honda, H. Itoh, J. Inoue, H. Yanagihara, E. Kita, and K. Mibu, Phys. Rev. B 84, 104407 (2011).

${ }^{22}$ G. Bertoni, L. Calmels, A. Altibelli, and V. Serin, Phys. Rev. B 71, 075402 (2005).

${ }^{23}$ Z. Szotek, W. M. Temmerman, D. Kodderitzsch, A. Svane, L. Petit, and H. Winter, Phys. Rev. B 74, 174431 (2006).

${ }^{24}$ V. C. Rakhecha and N. S. SatyaMurthy, J. Phys. C 11, 4389 (1978).

${ }^{25}$ H. Yang, C. Jin, W. B. Mi, H. L. Bai, and G. F. Chen, J. Appl. Phys. 112, 063925 (2012).

${ }^{26}$ Yu. S. Dedkov, U. Rüdiger, and G. Güntherodt, Phys. Rev. B 65, 064417 (2002).

${ }^{27}$ M. I. Katsnelson, V. Y. Irkhin, L. Chioncel, A. I. Lichtenstein, and R. A. de Groot, Rev. Mod. Phys. 80, 315-378 (2008). 